\title{
ANÁLISE DE MATERIAIS EM DESIGN DE INTERIORES
}

MATERIALS ANALYSIS IN INTERIOR DESIGN

\section{Tatiana Zacheo Rodrigues, M.Sc. (UNOCHAPECÓ); \\ Angelis Gregory (UNOCHAPECÓ).}

\author{
Palavras Chave \\ Sustentabilidade, Design de Interiores, Materiais. \\ Key Words \\ Sustentability, Interior Design, Materials.
}

\section{RESUMO}

A quantidade de estabelecimentos comerciais que investem para ter um posicionamento favorável à sustentabilidade se mostra crescente. No mesmo sentido é o aumenta da complexidade de projeto para o designer de interiores, visto que há inúmeras opções de materiais em oferta no mercado. Neste estudo foi observado um restaurante que se apresenta como um local sustentável. Sendo assim, buscou-se qualificar o design de interiores do local com base em princípios bibliográficos de sustentabilidade. Foi realizada análise de materiais especificados para revestimentos de piso, parede e tetos dos ambientes comuns, além de mobiliários, elementos arquitetônicos internos e decorações. $\mathrm{O}$ design de interiores deste estabelecimento se destacou pelo uso de materiais de origem renovável. No entanto não houve percepção de outros conceitos de sustentabilidade, como redução e reutilização. A carência de informações técnicas de diversos materiais deu ao estudo exploratório um caráter empírico.

\section{ABSTRACT}

The amount of businesses that invest to have a position in favour of sustainability is increasing. Also increases the complexity of the project design for the interior designer, since there are countless options of materials on offer on the market. The restaurant studied presents itself as a sustainable site, thus sought to qualify the local interior design based on bibliographic principles of sustainability, evaluating materials specified for floorings, wall and ceilings of common environments, in addition to furniture, architectural elements and decorations. The interior design of this establishment stood out by the use of renewable materials, however there was no perception of other concepts of sustainability, such as reduction and reuse. The lack of technical information of various materials gave the study an empirical character. 


\section{INTRODUÇÃO}

A quantidade de estabelecimentos comerciais que investem para ter um posicionamento favorável à sustentabilidade aumenta junto com a conscientização da população que é necessário repensar a forma de produção, consumo e reuso dos materiais. Em paralelo a essa situação, aumenta a complexidade de projeto para o designer de interiores, visto que há inúmeras opções de materiais em oferta no mercado. Nesse sentido que surgiu o objetivo de escolher um estabelecimento tipo restaurante que se apresenta como um local sustentável para conquistar uma imagem agradável e madura aos seus frequentadores. No entanto, como saber se é apenas um posicionamento estratégico de marketing ou foram utilizados conceitos de sustentabilidade em todo seu design de interiores? Sendo assim, buscou-se qualificar o design de interiores do local com base em princípios bibliográficos de sustentabilidade, foi avaliado tipos de materiais especificados para revestimentos de piso, parede e tetos dos ambientes comuns, além de mobiliários, elementos arquitetônicos internos e decorações.

O local escolhido para análise da pesquisa utiliza como matéria-prima arquitetônica containers, que vincula sua imagem de marca com a sustentabilidade da edificação, visto que a mesma incorpora a reutilização como fator de destaque em seu branding. Cada vez mais percebe-se que as empresas procuram vincular sua marca com a sustentabilidade ao perceber que essa decisão as aproxima do consumidor. No entanto, ainda é complexo comprovar o que faz a empresa ser sustentável realmente. Inicialmente foi necessário realizar um filtro para identificar quais materiais são cabíveis de análise. Isso ocorre porque existem itens devem respeitar o que preconizam as normas brasileiras, como materiais elétricos, hidráulicos, balcões de preparo de alimentos, entre outros. Para tanto são analisados os revestimentos do salão e lavabos (piso, paredes e teto); o mobiliário, que consiste em mesas, cadeiras e louças sanitárias; e elementos arquitetônicos, como escada, corrimão, portas internas e luminárias. Antes de realizar o estudo de caso, a pesquisa bibliográfica visou identificar os materiais e as técnicas que são pertinentes ao design sustentável para embasar a análise coesa do objeto estudado. $\mathrm{O}$ trabalho consistiu portanto, em uma pesquisa teórico-prática, onde são identificados os quesitos de sustentabilidade aplicados num design de interiores comercial da cidade de Chapecó, SC. Então, ficou o objetivo do estudo, entender a sustentabilidade dos materiais do design de interiores utilizados numa tipologia comercial - restaurante com proposta de sustentabilidade em sua marca. O conteúdo das demais seções seguem pela Seção 2, Seção 3 e Seção 4. Sendo, a revisão bibliográfica sobre o tema na
Seção 2, fica apresentado conceitos básicos e reflexões do tema design de interior e sustentabilidade; o procedimentos metodológicos com os resultados do Estudo de Caso na Seção 3, onde serão apresentados os métodos adotados para o desenvolvimento da pesquisa apresentada no artigo bem como o uso de materiais encontrados no estudo de caso refletidos e analisados segundo autores e fontes acadêmicas; e, encerra, na seção 4 com as considerações finais do estudo. Ao final do artigo estão nomes de autores e de todos os demais referenciais bibliográficos e teóricos utilizados.

\section{MATERIAIS SUSTENTÁVEIS NO DESIGN}

Existem revistas científicas, artigos, trabalhos de conclusão de curso (TCC), dissertações, teses e livros que abordam o tema sustentabilidade. Ainda, pode-se destacar que as capas de revistas que falam sobre construção e reforma apresentam a importância de se pensar o reuso e a reciclagem no momento de criar um ambiente. Os profissionais que pensam projetos compreendem que suas decisões geram impactos, o mercado da construção civil gera impacto social e ambiental. No entanto, a bibliografia efetivamente contribui para que um designer de interiores encontre as soluções mais adequadas em seus projetos? Com foco na revisão de autores e no problema de pesquisa inicia-se a busca de respostas acadêmicas para que os profissionais de design de interiores possam evoluir nas reflexões para escolha de materiais.

\subsection{Design de Interiores Sustentável}

$O$ design de interiores afeta o meio ambiente de diversas formas, sendo que muitos profissionais trabaIham para mostrar como é possível incorporar princípios de sustentabilidade também aos ambientes internos. Moxon (2012 p. 29) afirma que a "tarefa útil dos materiais e facilitar a montagem/desmontagem (TUKKER, et al., 2006 apud FUKUSHIMA, 2009 p.22). O design industrial deve respeitar todos os condicionantes e inputs relevantes e aplicáveis: da ergonomia às disponibilidades técnicas de produção, da otimização dos recursos ao respeito pelo design de interiores afeta o meio ambiente de diversas formas, sendo que muitos profissionais trabalham para mostrar como é possível incorporar princípios de sustentabilidade também aos ambientes internos. Moxon (2012 p. 29) afirma que a "tarefa ambiente, da diminuição das emissões à integração de soluções inovadoras, do respeito pelos direitos do consumidor à materialização de uma forma equilibrada e harmoniosa (AGUIAR, 2008 apud LIBRELOTTO, et al., 2012, p.109).

Historicamente o trabalho de designers e arquitetos 
produziram resultados menos impactantes ao meio ambiente, segundo Moxon (2012). O autor afirma que isso se deve aos materiais e métodos construtivos serem locais e por serem explorados princípios de projeto bioclimático sendo, portanto, responsivos ao local e ao clima (MOXON, 2012). Pazmino (2007) afirma que a evolução tecnológica das últimas décadas aliada ao aumento do consumo e a busca por altos padrões de conforto levaram à degradação do meio ambiente, sendo necessária a intervenção do profissional designer para melhorar a relação estabelecida entre produtos, ambiente e sociedade. O autor destaca ainda a importância dos profissionais dessa área estarem conscientes dos problemas sociais e ambientais, já que a questão é discutida desde a década de 60 pelo designer norte-americano Victor Papanek.

Entre as décadas de 1980 e 1990 o termo sustentabilidade tornou-se bastante presente na sociedade, asseguram Gonçalves e Duarte (2006). Os autores também afirmam que o termo estava relacionado a uma possível crise energética de proporções mundiais e aos impactos ambientais decorrentes do uso intensivo de combustíveis fósseis, fatos agravados pelo inevitável crescimento da população mundial e das cidades, que aumentaram as demandas por outros recursos. Para Stuart (2005) há uma expectativa muito grande em reestruturar as noções de cultura material (consumo, produção, descarte, etc) e que o designer tem papel fundamental ao reconhecer sua importância nesse processo de reestruturação. O autor afirma que os designers deveriam criar uma 'tipologia estética' para produtos, visando reorganizar suas qualidades estéticas e as práticas insustentáveis nas quais eles são produzidos. Tal reorganização tem como finalidade estabelecer o que não deveria ser feito e incentivar a criação de formas alternativas, benignas e por fim, avanços para o design.

\subsection{Especificação de Materiais}

Quando pensamos nos materiais especificados nos projetos, temos à disposição diversas opções de matérias-primas, indústrias e marcas que oferecem características variadas, deixando o projetista a vontade para especificar de acordo com a necessidade de cada projeto/cliente. Porém, nem sempre foi assim, no século XVIII "os desenhos arquitetônicos raramente indicavam os materiais a serem usados na construção" afirma Vosgueritchian (2006, p.109), que complementa que foi a partir da segunda metade do século XIX - quando desenvolveram-se meios de transporte capazes de transportar a produção para locais longínquos (ferrovias, canais e estradas) verificou-se a produção em massa de diversos insumos e componentes
- que se disseminaram técnicas construtivas e materiais e a globalização fez com que arquitetos e designers pudessem buscar do outro lado do planeta materiais que satisfizessem suas necessidades projetuais. A evolução da indústria e da tecnologia gerou um leque variado de materiais, cuja classificação ocorre de acordo com as propriedades físicas, físico-químicas, formas de processamento, entre outras (LIMA, 2006). O autor divide os materiais em cinco grandes grupos, conforme a figura 1.

Figura 1: Classificação geral dos materiais e subgrupos.

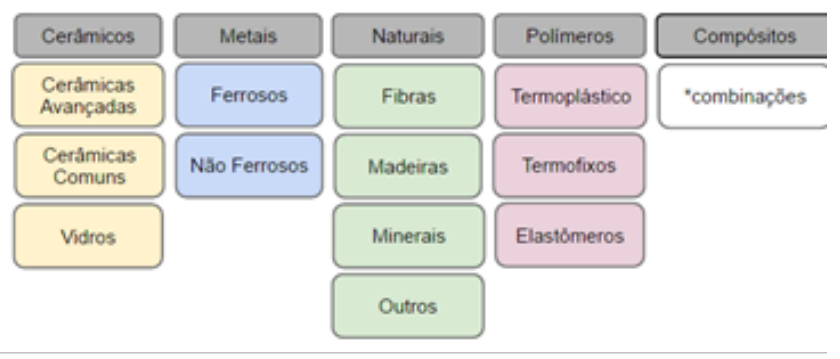

Fonte: Adaptado de Lima, 2006 p.4

As possibilidades de aplicação dos materiais cerâmicos é vasta e o Brasil possui elevadas quantidades de fontes para essa matéria-prima. O país possui uma indústria expressiva nesse setor, destacando-se a produção de revestimentos, louças sanitárias e de mesa, tijolos e telhas (LIMA, 2006). O autor relata que o processo de fabricação de qualquer material classificado como cerâmico inicia com a extração de material argiloso de jazidas, na sequência inicia o tratamento da matéria-prima, em etapas sucessivas, sendo que cada uma dessas etapas é diferenciada de acordo com o produto que se deseja obter. Ao fim do processo de tratamento há a moldagem, secagem e acabamento superficial das peças. Já os metais são materiais definidos quimicamente por existirem como cristal ou agregado de cristais em estado sólido. Suas características físicas são dureza, plasticidade/ductilidade, resistência à tração e compressão e boa condutividade térmica e elétrica (LIMA, 2006). A cerâmica está num grupo que pode ser interpretado como sustentável. Outro grupo que chapa atenção dos designers que procuram sustentabilidade são os materiais do grupo dos materiais naturais - aqueles que tem origem vegetal, animal ou mineral que são extraídos da natureza de forma planejada ou não, cujo processamento não altera as características básicas (LIMA, 2006). O autor afirma que por um determinado período os materiais naturais foram substituídos por materiais sintéticos, fato justificado pelas facilidades de produção em massa dos sintéticos e pelo fato dos materiais 
naturais não suportarem determinados esforços e intempéries. Nesse momento entram os dilemas sobre qual material realmente apresenta maior sustentabilidade num projeto de design de interiores.

Com a sustentabilidade em voga, a linha de produtos que utiliza recursos naturais apresenta mais valor e apelo, visto que são passíveis de renovação natural. No entanto, os polímeros - orgânicos ou inorgânicos e naturais ou sintéticos - são itens que entram como ameaça a sustentabilidade pelas suas fontes de extração e pelos processos produtivos. Os polímeros são derivados do petróleo ou do gás natural (LIMA, 2006). E, ainda segundo o mesmo autor, são classificados em termoplásticos, termofixos e elastômeros. Outro grupo que se destaca no grupo dos "avanços produtivos" são os compósitos. Esse último grupo é da classe de materiais que representa a evolução da humanidade, segundo Callister (2008). Tal evolução que fez com que surgissem demandas por materiais cujas propriedades não existem naturalmente (CALLISTER, 2008). $\mathrm{O}$ autor afirma que esse grupo de materiais são a combinação artificial de materiais existentes, objetivando unir suas melhores propriedades e transformá-los em um material com as propriedades desejadas.

Os designers têm a sua disposição um vasto leque de possibilidades para aplicação de materiais condizentes com a sustentabilidade. Para analisar cada material do ponto de vista ambiental é necessário também entender conceitos de energia incorporada e análise do ciclo de vida. Sobre o processo de criação dos designers no que tange a especificação de materiais Moxon $(2012$, p.94) enfatiza que algumas perguntas precisam ser feitas para garantir a sustentabilidade na escolha dos materiais, são elas:

onde o material escolhido foi processado/fabricado? Qual é a energia incorporada à sua produção? Quais os impactos ambientais gerados? A embalagem do material condiz com os conceitos sustentáveis? A aplicação do material demanda energia ou tem grandes impactos ambientais? Sua manutenção demanda produtos tóxicos? Ele poderá ser reutilizado ou reciclado sem grandes impactos ao meio ambiente?

Ao especificar materiais sustentáveis, o designer de interiores deveria primeiro considerar a redução, depois a reutilização, a reciclagem e, finalmente, o uso de fontes renováveis (MOXON, 2012). O autor cita exemplos: a prioridade é reduzir a quantidade de materiais utilizados (como, por exemplo, evitar o assentamento de um novo piso sobre o existente); especificar materiais de reuso, como madeira de demolição; quando novos materiais são necessários é importante escolher aqueles que possuem conteúdo reciclável; e, como última alternativa, quando não houver possibilidade a não ser utilizar materiais novos, que sejam escolhidos aqueles cujas matérias-primas são originárias de fontes renováveis. Outro fator que poderá ajudar num projeto sustentável de design de interiores são os certificados. Internacionalmente há certificados que avaliam o nível de sustentabilidade dos materiais e das empresas que os produzem, um deles é a ISO (International Organization for Standardization), certificação internacional que define requisitos gerais e procedimentos para diversos tipos de avaliação.

\subsection{Energia e Análise do ciclo de vida}

É sabido que a produção de insumo necessita consumo de energia e que esse consumo é verificado também durante todas as fases da vida de um material, desde a aquisição dos recursos naturais à energia utilizada para o feitio e funcionamento dos equipamentos que produzirão um objeto (VOSGUERITCHIAN, 2006). À somatória de todos os gastos energéticos envolvidos nas etapas de vida dos materiais é dado o nome de energia incorporada do material. De acordo com Graf e Tavares (2012) o cálculo da energia incorporada é utilizado para mensurar o impacto ambiental das construções, sendo considerado um forte indicador de sustentabilidade. Em relação à técnica de análise do ciclo de vida CHEHEBE (1998) apresenta como sendo uma técnica para avaliação dos aspectos ambientais e dos impactos potenciais associados a um produto, compreendendo etapas que vão desde a retirada da natureza das matérias-primas elementares que entram no sistema produtivo (berço) à disposição do produto final.

Serrador (2008) define que o método da Análise do Ciclo de Vida é aceito internacionalmente para qualificar o total de efeitos ambientais associados aos produtos, desde a extração de matérias-primas até a manufatura e transportes, instalação, uso e manutenção de um edifício, sua disposição final e reuso. Trata-se portanto, de uma abordagem de gerenciamento para reduzir os impactos gerados por um produto ou atividade com foco no meio ambiente e na saúde humana. Ferreira (2004) afirma que cada etapa da produção de determinado bem impacta ambientalmente. Pazmino (2007) define design sustentável como aquele no qual o produto é ambientalmente correto, economicamente viável e socialmente equitativo, apresentando uma versão ampliada dos itens a serem observados no desenvolvimento/produção de um produto.

\section{METODOLOGIA}

O método utilizado foi exploratório. Foi realizada pesquisa em campo com coleta de dados primários como 
memorial descritivo e foram registradas fotografias após observação do local. Após, realizou-se pesquisa em bibliografias para compreender os impactos dos materiais escolhidos bem como as características que os materiais encontrados apresentam. A busca foi por aprendizagem para possível compartilhamento de conhecimento via "boas práticas" visto que foi selecionado um local que se apresenta com uma marca sustentável. No próximo item, estudo de caso, ficam listadas e explicadas todas as etapas para a realização da pesquisa.

\subsection{Estudo de Caso}

Nessa etapa buscou-se identificar a relação dos materiais utilizados no objeto estudado. Os materiais selecionados para análise foram piso, parede e teto das áreas comuns, mobiliário e elementos arquitetônicos. $O$ estudo foi realizado com base no que as bibliografias apresentam sobre o material identificado, e deve seguir três etapas: 1) análise dos materiais no design de interiores: identificar quais os materiais utilizados em cada elemento aplicado para design de interiores; 2) analisar as opções adotadas e proposição de alternativas que elevariam o nível de sustentabilidade do edifício.

Foram realizadas visitas presenciais e análise de materiais cedidos pelos projetistas do espaço.

\subsection{Análise dos Materiais}

A etapa inicial consiste em identificar todos os materiais utilizados nos ambientes comuns do ambiente. $\mathrm{O}$ processo de identificação dos materiais ocorreu a partir de dados fornecidos pelo memorial descritivo de projeto, cedido pela empresa responsável pelo desenvolvimento do projeto, e por três visitas técnicas ao local, realizadas por uma das autoras que é formada em arquitetura. A análise ocorreu no mês de novembro de 2015 e os dados coletados são apresentados na tabela 1.
Tabela 1: Materiais especificados na unidade Chapecó da franquia.

\begin{tabular}{|c|c|c|}
\hline Ambiente & Elemento & Material \\
\hline \multirow[t]{3}{*}{$\begin{array}{l}\text { Salão térreo } \\
\text { e superior }\end{array}$} & Piso e Parede & $\begin{array}{l}\text { Painel de madeira } \\
\text { Muirapiranga e } \\
\text { falso Pau-Brasil } \\
\text { em palitos de } \\
\text { 0,014x1,8x22cm, } \\
\text { colados na ver- } \\
\text { tical, com apli- } \\
\text { cação de verniz } \\
\text { fosco retardante } \\
\text { anti-chamas para } \\
\text { madeira, NFW } \\
\text { WOOD CLASSE A, } \\
\text { laudo IPT ensaio } \\
\text { no } 890229\end{array}$ \\
\hline & Teto & $\begin{array}{l}\text { Chapa de aço ori- } \\
\text { ginal do container } \\
\text { com pintura es- } \\
\text { malte semi-brilho } \\
\text { anti corrosiva }\end{array}$ \\
\hline & Portas & $\begin{array}{l}\text { MDF melamínico } \\
\text { fresno preto }\end{array}$ \\
\hline \multirow[t]{2}{*}{ Escada } & Degraus & $\begin{array}{l}\text { Chapa de ferro } \\
\text { corrugada (xa- } \\
\text { drez) com pintura } \\
\text { em tinta esmalte } \\
\text { anticorrosiva e } \\
\text { incombustível na } \\
\text { cor preta }\end{array}$ \\
\hline & Corrimão & $\begin{array}{l}\text { Barras de ferro } \\
50 \mathrm{~mm} \text { com pintu- } \\
\text { ra preta }\end{array}$ \\
\hline
\end{tabular}

Fonte: Autoras 
Tabela 1: Materiais especificados na unidade Chapecó da franquia.

\begin{tabular}{|c|c|c|}
\hline Ambiente & Elemento & Material \\
\hline \multirow{3}{*}{ Lavabos } & Piso & $\begin{array}{l}\text { Porcelanato polido } \\
\text { preto } 60 \times 60 \mathrm{~cm} \text {, } \\
\text { gloss, retificado, } \\
\text { tonalidade } 130, \\
\text { aplicado com } \\
\text { argamassa sobre } \\
\text { o piso original do } \\
\text { container }\end{array}$ \\
\hline & Parede e Teto & idem salão \\
\hline & Bancadas & Granito polido \\
\hline \multirow{4}{*}{$\begin{array}{l}\text { Mobiliário } \\
\text { e Decorações }\end{array}$} & $\begin{array}{l}\text { Tampos de } \\
\text { Mesa }\end{array}$ & $\begin{array}{l}\text { MDF preto e torras } \\
\text { de madeira }\end{array}$ \\
\hline & $\begin{array}{l}\text { Base de } \\
\text { Mesa }\end{array}$ & $\begin{array}{l}\text { Ferro tubular } \\
\text { 100mm e barras } \\
\text { de ferro } 10 \mathrm{~mm} \\
\text { agrupadas }\end{array}$ \\
\hline & Cadeiras & $\begin{array}{l}\text { Assento em } \\
\text { madeira lamelada } \\
\text { colada. } \\
\text { Pé fixo em ferro } \\
\text { tubular } 100 \mathrm{~mm}\end{array}$ \\
\hline & $\begin{array}{l}\text { Prateleiras } \\
\text { decorativas }\end{array}$ & MDF Preto \\
\hline
\end{tabular}

Fonte: Autoras

O design de interior se depara com um leque de opções de materiais para avançar na escolha ideal do material que gera o menor impacto ambiental. O ciclo de vida do produto é complexo e pode acontecer uma interpretação errônea ao avaliar apenas o ciclo final que permite uma reciclagem futuro ou apenas refletindo se provem do grupo dos materiais naturais.

\subsection{Qualificação dos materiais}

Após identificar os materiais que compõem o projeto de interiores do salão e lavabos, opta-se por caracterizá-los em forma de tabela, onde lado a lado são apontados os quesitos positivos e negativos de cada material. Para cada material são analisados itens como processo de fabricação, formas de extração, origem, durabilidade, possibilidade de reúso ou reciclagem, formas de manutenção, propriedades térmicas e acústicas, entre outros quesitos específicos de cada material. Devido a escassez de informações e dificuldades em identificar alguns dos elementos existentes, optou-se por caracterizar apenas os materiais que puderam ser identificados. Resultado apresentado na tabela 2, abaixo.

Tabela 2: Caracterização dos Materiais.

\begin{tabular}{|c|c|c|}
\hline Material & $\begin{array}{l}\text { Pontos } \\
\text { Positivos }\end{array}$ & $\begin{array}{c}\text { Pontos } \\
\text { Negativos }\end{array}$ \\
\hline $\begin{array}{c}\text { Painel de } \\
\text { Muirapiranga e } \\
\text { falso Pau-Brasil }\end{array}$ & $\begin{array}{l}\text {-É reciclável; } \\
\text {-biodegradável; } \\
\text {-Provém de } \\
\text { matéria-prima } \\
\text { renovável; } \\
\text {-Baixo nível } \\
\text { de energia in- } \\
\text { corporado em } \\
\text { seus processos; } \\
\text {-É um bom iso- } \\
\text { lante térmico; } \\
\text {-Boa resistên- } \\
\text { cia a fungos } \\
\text { e cupins; } \\
\text { (MARQUES, } \\
\text { 2008, p.52) }\end{array}$ & $\begin{array}{l}\text {-Ocorre nas } \\
\text { regiões Norte e } \\
\text { Nordeste do país; } \\
\text {-Seu transporte } \\
\text { gera emissões de } \\
\text { gases poluentes e } \\
\text { de efeito estufa; } \\
\text {-Não provenien- } \\
\text { te de manejo } \\
\text { sustentável; } \\
\text { (LIMA, 2006, p.98) }\end{array}$ \\
\hline $\begin{array}{c}\text { Porcelanato } \\
\text { Polido }\end{array}$ & $\begin{array}{l}\text {-Produção local; } \\
\text {-Disponibilidade } \\
\text { de matéria-prima; } \\
\text { (CALLISTER,2008, } \\
\text { p.334) }\end{array}$ & $\begin{array}{l}\text { Demanda grandes } \\
\text { quantidades de } \\
\text { energia para } \\
\text { produção; } \\
\text {-Geração de gases } \\
\text { advindos da quei- } \\
\text { ma, um processo } \\
\text { inevitável para } \\
\text { produção, } \\
\text {-Possibilidade de } \\
\text { reaproveito nula; } \\
\text { (LIMA, 2006, p.123) }\end{array}$ \\
\hline
\end{tabular}


Tabela 2: Caracterização dos Materiais.

\begin{tabular}{|c|c|c|}
\hline Material & $\begin{array}{l}\text { Pontos } \\
\text { Positivos }\end{array}$ & $\begin{array}{c}\text { Pontos } \\
\text { Negativos }\end{array}$ \\
\hline Pintura esmalte & $\begin{array}{l}\text {-Proteção con- } \\
\text { tra corrosão ; }\end{array}$ & $\begin{array}{l}\text {-Presença de } \\
\text { VOC's (Compostos } \\
\text { orgânicos } \\
\text { voláteis); }\end{array}$ \\
\hline $\begin{array}{c}\text { MDF } \\
\text { Melamínico }\end{array}$ & $\begin{array}{l}\text {-Facilidade de } \\
\text { manuseio; } \\
\text {-Produção } \\
\text { a partir de } \\
\text { madeiras de re- } \\
\text { florestamento; } \\
\text { (BRAND, 2004, } \\
\text { p.555) }\end{array}$ & $\begin{array}{l}\text {-Grande gera- } \\
\text { ção de resíduos } \\
\text { no processo } \\
\text { produtivo; } \\
\text { (BRAND, 2004, } \\
\text { p.554) }\end{array}$ \\
\hline $\begin{array}{c}\text { Chapa de ferro } \\
\text { corrugada } \\
\text { (xadrez) e } \\
\text { Barras de ferro } \\
50 \mathrm{~mm}\end{array}$ & $\begin{array}{l}\text {-Possibilidade } \\
\text { de reciclagem } \\
\text { (CALLISTER, } \\
\text { 2008, p.128); }\end{array}$ & $\begin{array}{l}\text {-Geração de gás } \\
\text { carbônico; } \\
\text {-Contaminação de } \\
\text { recursos hídricos; } \\
\text {-Deterioração de } \\
\text { fauna e flora; } \\
\text {-Alto consumo } \\
\text { energético; (LIMA, } \\
\text { 2006, p.226); }\end{array}$ \\
\hline $\begin{array}{l}\text { Madeira lamela- } \\
\text { da colada }\end{array}$ & $\begin{array}{l}\text { - Provém de } \\
\text { matéria-prima } \\
\text { renovável }\end{array}$ & $\begin{array}{l}\text {-Utilização de resi- } \\
\text { nas poluentes }\end{array}$ \\
\hline
\end{tabular}

Fonte: Autoras

A carência de bibliografias sobre alguns materiais como madeira laminada colada, MDF melamínico, entre outros e as técnicas de fabricação, manutenção e descarte dificultaram a avaliação do projeto num contexto mais amplo e aprofundado. Numa avaliação empírica do ambiente comum do restaurante nota-se um forte apelo ao meio ambiente pela utilização da madeira como revestimento presente no piso e paredes. As propriedades desse material, como apresentado na tabela 2, validam-no enquanto resposta positiva às questões ambientais. Em contrapartida, a origem dessa madeira é questionável, visto que ocorre extração das mesmas em regiões distantes do local fim e, provavelmente, não oriunda de práticas de manejo sustentáveis.

Pode-se concluir que materiais "antigos" são sustentáveis. Transmitem ideia de reaproveitamento e reuso porque remeter aos processos tradicionais. As chapas e barras de ferro, ver imagem 2, Mas, segundo avaliação de aspectos negativos percebe-se que a chapa e a barra de ferro apresenta contaminação de recursos hídricos em seu ciclo de vida, deterioração de fauna e flora, alto consumo de energia elétrica e geração de carbono segundo Lima (2006). Sendo assim, apesar de possibilidade de reciclagem (CALLISTER, 2008), precisa ser pensado se o projeto de interior está extraindo novos recursos ou realmente reciclando algo que já foi produzido inicialmente. Isso muda o todo impacto ambiental e social na escolha do material.

Figuras 2: Chapas e Barras de ferro

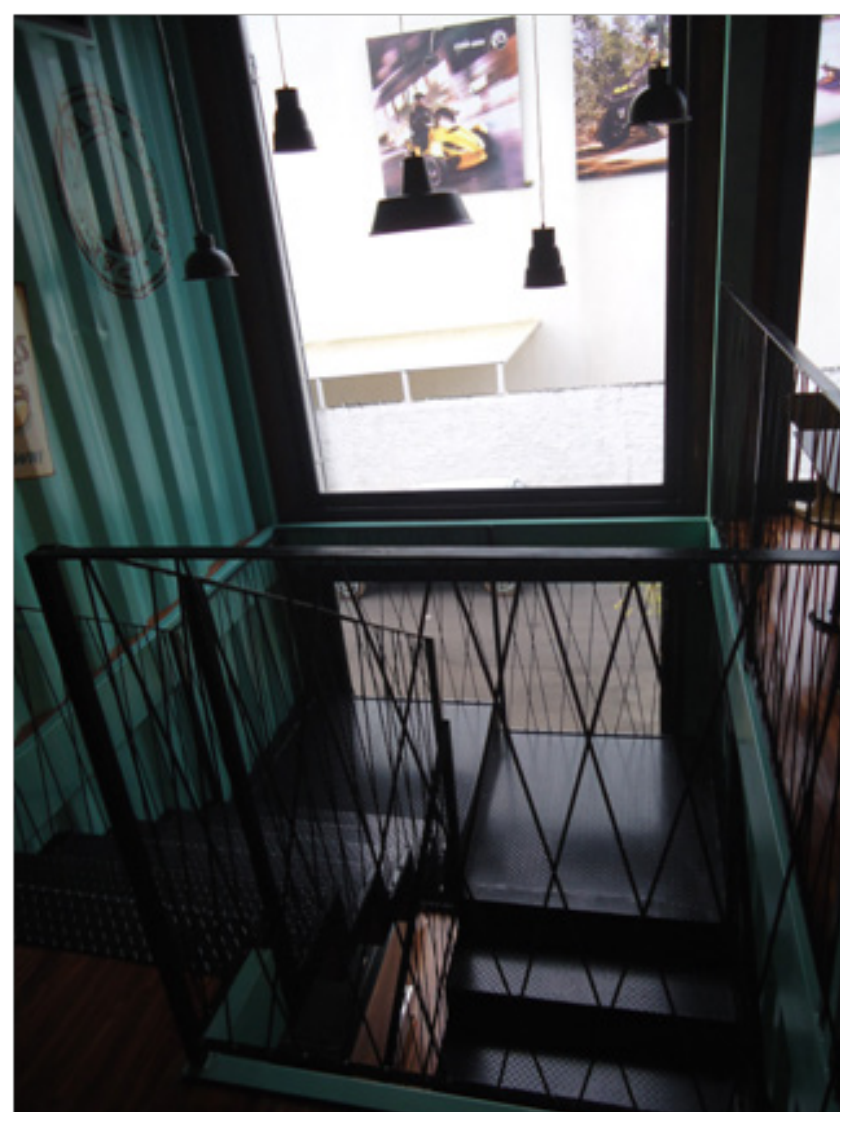

Fonte: Autoras

Outros elementos, presentes em menor escala, tais como tampos de mesa e portas internas, ambos executados em MDF apresentam-se como pontos favoráveis à sustentabilidade. Alguns dos tampos de mesa são executados com toras de madeiras fatiadas, ver figura 3. Ao refletir sobre o processo de crescimento das árvores, seja qual for a espécie, sabe-se que um tronco de aproximadamente $80 \mathrm{~cm}$ de diâmetro precisa de décadas ou até mesmo centenas de 
anos para atingir tal proporção. Sendo assim, a sua utilização vai contra qualquer quesito de sustentabilidade.

Figuras 3: Madeira e afins

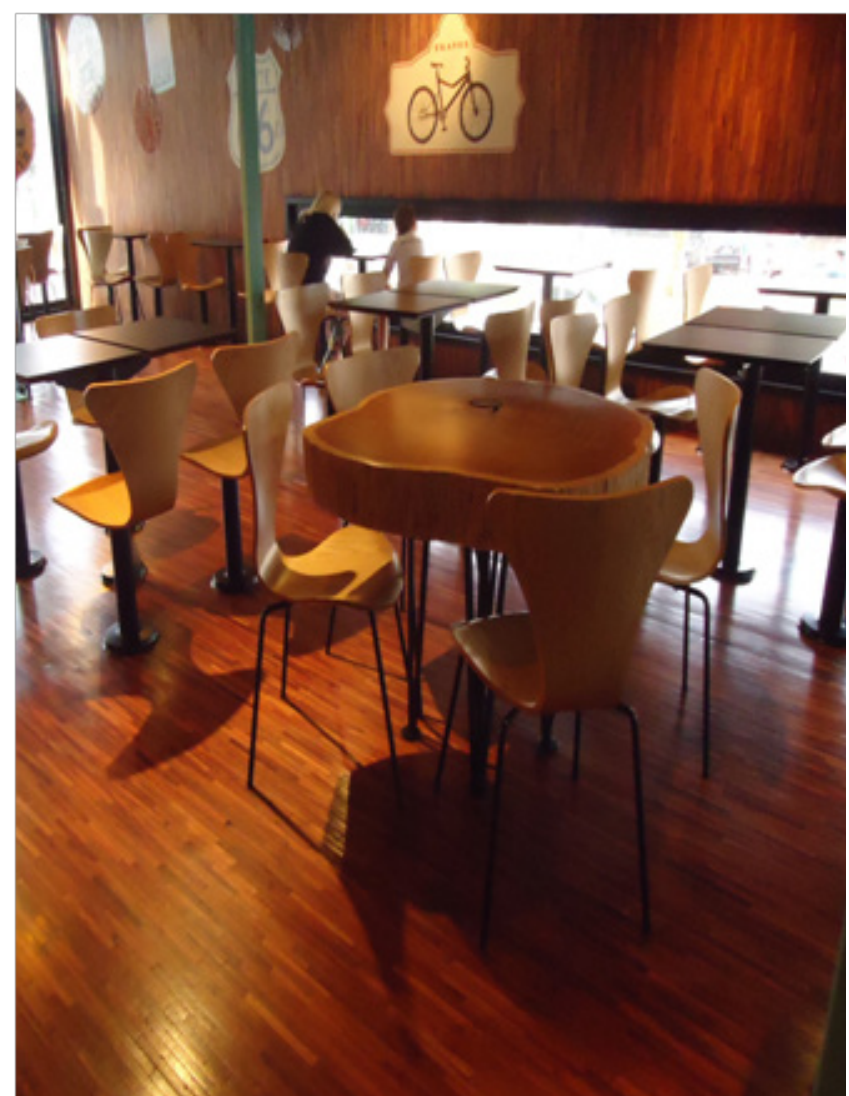

Fonte: Autoras

Materiais cerâmicos são utilizados em menor escala, apenas no piso dos lavabos. De acordo com a bibliografia pesquisada são materiais que demandam grandes quantidades de energia em seus processos e que apesar de serem provenientes da região sul, possuem um alto grau de degradação ambiental em suas fases de extração e produção. No entanto, vale ressaltar que o uso de materiais cerâmicos em espaços de higiêne pessoal não é facultativo visto que se apresenta como uma prática comum e sem opções alternativas no mercado atual que oferece material de construção civil, ver figura 4.

As bases de mesas, bancos e cadeiras são executados em perfis e tubos de ferro de diferentes bitolas e recebem pintura com tinta esmalte preta. Sabendo que a reutilização ou reciclagem de um bem torna-se mais difícil quando na presença de produtos químicos, tem-se um ponto negativo, porém a proteção gerada por esses elementos prolonga a vida útil do bem.

Após a análise dos pontos positivos e negativos inerentes aos materiais utilizados no design de interiores do restaurante, percebeu-se que embora existam atributos sustentáveis na maioria deles, os mesmos não se justificam devido a sua produção e/ou extração. Outro ponto a ser destacado é que, por se tratar de uma rede de restaurantes não existe a preocupação em utilizar materiais e técnicas locais, sendo a maioria dos insumos provenientes do local de origem da franquia.

Figuras 4: Cerâmica

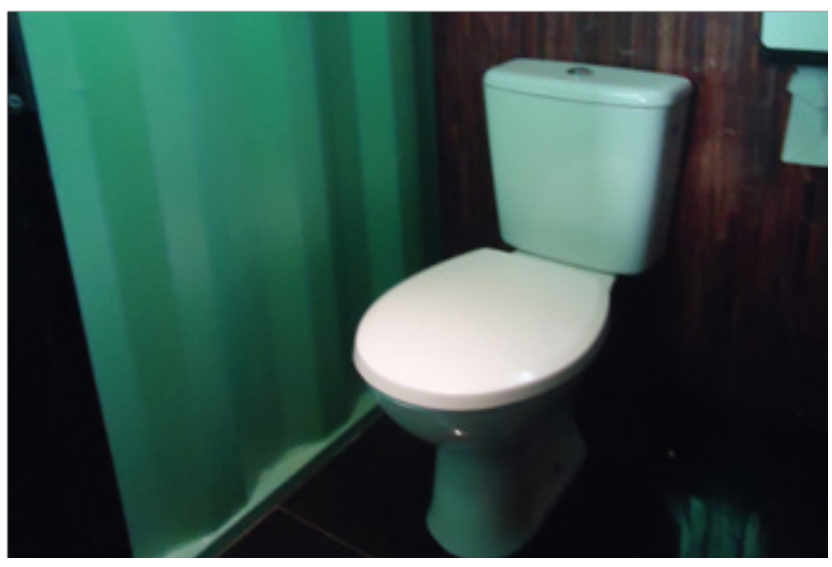

Fonte: Autoras

As bases de mesas, bancos e cadeiras são executados em perfis e tubos de ferro de diferentes bitolas e recebem pintura com tinta esmalte preta. Sabendo que a reutilização ou reciclagem de um bem torna-se mais difícil quando na presença de produtos químicos, tem-se um ponto negativo, porém a proteção gerada por esses elementos prolonga a vida útil do bem.

Após a análise dos pontos positivos e negativos inerentes aos materiais utilizados no design de interiores do restaurante, percebeu-se que embora existam atributos sustentáveis na maioria deles, os mesmos não se justificam devido a sua produção e/ou extração. Outro ponto a ser destacado é que, por se tratar de uma rede de restaurantes não existe a preocupação em utilizar materiais e técnicas locais, sendo a maioria dos insumos provenientes do local de origem da franquia.

\section{CONSIDERAÇÕES FINAIS}

Ao finalizar análise e estudo - a partir do memorial descritivo do projeto e coleta de dados in loco - percebe-se que as indústrias de bens voltados à construção civil e design de interiores precisam evoluir de maneira que seus processos produtivos, extração de matéria-prima e formas de instalação visem a redução de materiais e aumentem a quantidade e a qualidade de informações técnicas disponibilizadas ao mercado. Entende-se que o primeiro passo para a geração de propostas de projetos que 
tenham o design de interiores com fundamentos sustentáveis é o acesso a informação, através de dados técnicos dos produtos. Sem tais informações as decisões de projeto ocorrem as cegas e de forma empírica. Infelizmente, não há como garantir que apenas ao escolher um material do grupo dos naturais ou cerâmicos se está fazendo um design sustentável. As decisões não são e não devem acontecer de forma amadora.

Dessa forma tornou-se difícil responder à questão do trabalho, que visa identificar qual a resposta do design de interiores frente a sustentabilidade. Outro fator que dificulta uma análise mais completa é o fato de não estar definido o destino de cada material especificado, visto que podem ou não ser reutilizados/reciclados. Sendo assim, fica como sugestão de pesquisas futuras a análise do ciclo de vida dos materiais para o design de interiores bem como estudos sobre qual metodologia de projeto foi utilizada para a criação do ambiente.

O design de interiores do estabelecimento se destacou pelo uso de materiais de origem renovável, no entanto não houve percepção de outros conceitos de sustentabilidade, como redução e reutilização. A carência de informações técnicas de diversos materiais deu ao estudo um caráter empírico.O papel do design de interiores frente à sustentabilidade de uma edificação comercial tende a ganhar destaque estratégico visto que as opções de materiais não devem ser apenas por senso estético.

Os profissionais da construção civil, arquitetura e design apresentam impacto na humanidade e na ecologia quando optam por determinado material e processo de fabricação. Ainda, os impactos indiretos sociais e ambientais são diversos ao definir o local de extração da matéria-prima e o tipo de mão-de-obra envolvida no processamento dos materiais. Ou seja, os projetos não atendem apenas o consumidor final ao torná-lo satisfeitos com o ambiente. Fica claro que a seleção de materiais apresenta consequências para toda a sociedade.

\section{REFERÊNCIAS}

BRAND, Martha A.; KLOCK, Umberto; MUNIZ, Graciela I. B.; SILVA, Dimas A. Avaliação do processo produtivo de uma indústria de manufatura de painéis por meio do balanço de material e do rendimento da matéria-prima. In: Sociedade de Investigações Florestais, 2004, Viçosa. Disponível em: <http://www.scielo.br/pdf/rarv/ v28n4/22604.pdf > consultado em 03 dez. 2015

CALLISTER, William D. Jr. Ciência e Engenharia de Materiais: uma introdução/ William D. Callister
Jr.:tradução Sérgio Murilo Stamile Soares. - Rio de Janeiro: LTC, 2008. 693p.

CHEHEBE, José Ribamar B. Análise do ciclo de vida de produtos: ferramenta gerencial da ISSO 14000 . Rio de Janeiro: Qualitymark Ed. 1998.104p

FERREIRA, José V. R. Análise do Ciclo de Vida dos Produtos. Instituto Politécnico de Viseu. 2004 80p.

FUKUSHIMA, Naotake. Dimensão Social do Design Sustentável: Contribuições do Design Vernacular da População de Baixa Renda. 2009. 160 p. Dissertação (Mestrado em Design) - Universidade Federal do Paraná, Curitiba, 2009.

GONÇALVES, Joana C. S.; DUARTE, Denise H. S. Arquitetura sustentável: uma integração entre ambiente, projeto e tecnologia em experiências de pesquisa, prática e ensino. Ambiente Construído, Porto Alegre, v. 6, n. 4, p. 51-81 out./dez. 2006.

GRAF, Helena F; TAVARES, Sergio F. Energia Incorporada dos Materiais de uma Edificação Padrão Brasileira Residencial. III Congresso de Inovação, Tecnologia e Sustentabilidade. UNIFEBE. 2012.

LIBRELOTTO, Lisiane I. A Teoria do Equilíbrio: alternativas para a sustentabilidade na construção civil/Lisiane Ilha Librelotto et all... - Florianópolis: DIOESC, 2012. 350p.

LIMA, Antonio M. Introdução aos Materiais e Processos para Designers. Rio de Janeiro: Editora Ciência Moderno Ltda., 2006. 225p.

MARQUES, Luis Eduardo M. M. O Papel da Madeira na Sustentabilidade da Construção. 2008. 111 p. Dissertação (Mestrado em Engenharia Civil) - Faculdade de Engenharia da Universidade do Porto, 2008.

MOXON, Siân. Sustentabilidade no Design de Interiores. São Paulo: Gustavo Gili. 2012. 191p.

PAZMINO, Ana V. Uma reflexão sobre Design Social, Eco-Design e Design Sustentável. In: SIMPÓSIO BRASILEIRO DE DESIGN SUSTENTÁVEL, 1., 2007, Curitiba. Disponível em: <http://editorainsight.com.br/naolab/wp-content/uploads/2012/03/PAZMINO2007-DSocial-EcoDe-DSustentavel.pdf> 
SERRADOR, Marcos Eduardo. Sustentabilidade em arquitetura: referências para projeto.2008. 267p. Dissertação (Mestrado em Arquitetura e Urbanismo) Escola de Engenharia de São Carlos, Universidade de São Paulo, São Carlos, 2008

STUART, Walker. Desmascarando o objeto: reestruturando o design para a sustentabilidade. Revista Design em Foco, vol II, núm. 2, julho-dezembro, 2005, pp. 47-62. Universidade do Estado da Bahia, Bahia, Brasil.

VOSGUERITCHIAN, Andrea B. A abordagem dos sistemas de avaliação de sustentabilidade da arquitetura nos quesitos ambientais de energia, materiais e água, e suas associações às inovações tecnológicas. Dissertação - FAUUSP. São Paulo, 2006. 